\title{
DESAFIOS DA EDUCAÇÃO POPULAR EM CONTEXTOS DE PRIVAÇÃO DE LIBERDADE
}

\section{CHALLENGES OF POPULAR EDUCATION IN CONTEXTS OF PRIVACY OF FREEDOM}

\author{
Ana Claudia Ferreira Godinho \\ Doutora em Educação com pós-doutorado em Educação em Contextos de Privação de Liberdade. \\ Professora adjunta da Faculdade de Educação da Universidade Federal do Rio Grande do Sul. \\ Professora colaboradora do Programa de Pós-Graduação em Educação da Universidade do Estado de \\ Minas Gerais. \\ anaclaudia.godinho@gmail.com \\ Elionaldo Fernandes Julião \\ Doutor em Ciências Sociais. \\ Professor do Programa de Pós-Graduação em Educação. \\ elionaldoj@yahoo.com.br \\ Elenice Cammarosano Onofre \\ Doutora em Educação. \\ Professora do Programa de Pós-Graduação em Educação da \\ Universidade Federal de São Carlos. \\ linocam@uol.com.br
}

\begin{abstract}
Resumo: É possível a educação, em contextos de privação de liberdade, constituir-se como educação dialógica, como prática de liberdade? Este questionamento provoca reflexões sobre as possibilidades de análise da educação em contextos de privação de liberdade à luz dos principais aspectos desenvolvidos por Paulo Freire, na obra Pedagogia do oprimido. A partir da análise da obra, propomos o debate sobre a educação implementada para jovens e adultos em situação de privação de liberdade, com o objetivo de problematizar as possibilidades de reflexão sobre a educação em contextos de privação de liberdade à luz de conceitos e categorias desenvolvidos por Paulo Freire. Para refletir sobre as possibilidades de leitura da Pedagogia do oprimido e os desafios da educação popular em contextos de privação de liberdade, dialogamos com alguns estudos das ciências sociais, principalmente com os que refletem sobre o sistema prisional na sociedade contemporânea. Dentre os achados no estudo, o principal, nos parece, é resgatar a afirmação aparentemente óbvia da humanidade que, quando reduzida na prisão, afeta toda a sociedade, uma vez que o cárcere não é uma instituição isolada do mundo; ela faz parte da sociedade.
\end{abstract}

Palavras-Chave: Educação. Oprimido. Pedagogia. Popular. Prisão.

\begin{abstract}
Is it possible for education, in contexts of deprivation of freedom, to become a dialogical education, a practice of freedom? This question provokes reflections about the possibilities of analyzing education in contexts of deprivation of freedom under the main ideas developed by Paulo Freire, in his work Pedagogy of the oppressed. From an analysis of this book, we propose a debate on the education implemented for young people and adults in situations of restriction and deprivation of freedom. Through a dialogue with some academic texts in the areas of Education and Social Sciences on the prison system, we aim for a reflection on the possible readings of Pedagogy of the oppressed for the education in contexts of deprivation of freedom. The findings of our study emphasize the relevance of these concepts for the analysis of a popular education in contexts of deprivation of freedom. Its main aim is to rescue the (apparently obvious) affirmation of the humanity that, when reduced in prison, affects society as a whole, since prison is an institution which is not isolated from the world but part of society.
\end{abstract}

Keywords: Education. Oppressed. Pedagogy. Popular. Prison.

\section{Para citar - $(A B N T$ NBR 6023:2018)}

GODINHO, Ana Claudia Ferreira; JULIÃO, Elionaldo Fernandes; ONOFRE, Elenice Cammarosano.

Desafios da educação popular em contextos de privação de liberdade. Eccos - Revista Cientifica, São Paulo, n. 52, p. 1-19, e17100, jan./mar. 2020. Disponível em: https://doi.org/10.5585/eccos.n52.17100. 


\section{Apresentação}

É possível a educação em contextos de privação de liberdade constituir-se como educação dialógica, como prática de liberdade? Em outras palavras, seria possível pensar em articulações entre a perspectiva freiriana de "pedagogia do oprimido" e a educação com sujeitos em situação de privação de liberdade, justamente sobre o direito à liberdade?

Na Pedagogia do oprimido (1987), Paulo Freire aborda a educação como exercício de diálogo, autonomia e exercício de conscientização sobre o mundo e sobre o próprio sujeito, que o liberta da visão fatalista da sociedade e da história; educação que requer relações e interações humanas horizontais, pautadas pelo respeito e pelo reconhecimento do outro como sujeito da história, da cultura e da política. A privação de liberdade, por sua vez, em outra direção, remete à prisão, instituição constituída historicamente para privar a liberdade individual de quem é condenado por crime ou ato infracional, retirando-o do convívio com o restante da sociedade. Esta é uma contradição - não a única - da educação em contextos de privação de liberdade.

Entendemos as contradições não como impeditivas à reflexão sobre a articulação entre o pensamento freiriano e a educação em contextos de privação de liberdade. Ao contrário, a categoria contradição remete aos desafios que impulsionam a busca ontológica permanente por saber mais para ser mais, como nos ensinou Freire, em Educação e mudança (1979). Desse modo, esses desafios são o que nos mobilizam e nos fazem buscar conhecimentos para avançar. E os desafios não são poucos: garantir o direito à educação para os grupos sociais mais vulneráveis nos dias atuais, avançar no que diz respeito à qualidade da política de educação de jovens e adultos e resistir aos ataques de grupos conservadores contra os direitos humanos e outros.

A abordagem teórica do tema articula a educação popular e os estudos sobre educação em contextos de privação de liberdade, especialmente os das áreas da educação de jovens e adultos e das ciências sociais. Nosso objetivo, com este ensaio, é problematizar a educação em contextos de privação de liberdade à luz de conceitos desenvolvidos por Paulo Freire a partir da questão: - Como formular uma proposta de educação para jovens e adultos em contextos de privação de liberdade orientada pelos princípios desenvolvidos pelo autor?

Visando refletir sobre a implementação de uma proposta de Educação de Jovens e Adultos (EJA) ${ }^{1}$ em situação de privação de liberdade à luz de uma concepção de educação popular, buscamos promover um debate com alguns conceitos de Paulo Freire que emergem na sua obra Pedagogia do Oprimido. Nesse exercício de reflexão, buscamos promover o diálogo de alguns conceitos de Freire com estudos das ciências sociais que versam sobre a privação da 
liberdade na sociedade contemporânea, principalmente com as reflexões apresentadas por Goffman (1974), Wacquant (2011; 2009) e Garland (1999). Estes autores contribuem para a compreensão da prisão como instituição social que assume um papel central na criminalização e segregação das classes populares. Sua função social modifica-se no contexto de reestruturação produtiva e de consolidação do Neoliberalismo como modelo de organização do Estado e de sua relação com a sociedade civil e, principalmente, com a iniciativa privada e as grandes corporações do mercado.

Entre contradições e possibilidades, analisamos o que o sistema prisional apresenta como empecilhos, entraves que desacomodam e mobilizam a buscar novas alternativas, novos aliados e novas demandas para a formulação, ou para a efetiva implementação de políticas públicas que avancem na garantia de direitos da população em privação de liberdade - não raro a última a ser lembrada pelo Estado quando o tema é a criação de políticas sociais para os grupos mais vulneráveis e estigmatizados da sociedade. Infelizmente, esta invisibilização não sofre críticas da opinião pública; ao contrário, tem respaldo: afinal, 66\% da população brasileira considera que "os direitos humanos defendem mais os bandidos" que as vítimas, conforme pesquisa Pulso Brasil ${ }^{2}$ (2018).

\section{Possibilidades de Leitura da Pedagogia do oprimido para Reflexão sobre a Educação em Contextos de Privação de Liberdade}

As contradições nos permitem intervir e problematizar as relações sociais que constituem o mundo, as instituições, assim como nossas vidas e nosso modo de ler o mundo e a nós mesmos. É nessa direção que propomos refletir sobre as aproximações de dois campos educativos: a educação popular, baseada na Pedagogia do oprimido, portanto, pautada no diálogo e na liberdade como princípios inegociáveis do processo educativo que busca a consciência do mundo; e a EJA em contextos de privação de liberdade, aparentemente marcada por uma política que prima pela negação do direito humano à liberdade.

Partimos do princípio de que paira sobre o imaginário social a ideia de que o papel da prisão é de mera privação de liberdade dos indivíduos que cometeram algum crime ou ato infracional. Conforme previsto na legislação brasileira, principalmente na Lei de Execução Penal - LEP (Lei n. ${ }^{\circ} 7.210$, de 11 de julho de 1984) e no Art. 5. ${ }^{\circ}$ da Constituição Federal (1988), os sujeitos privados de liberdade só estão privados do direito de ir e vir, portanto, todos os demais direitos estão mantidos: "a inviolabilidade do direito à vida, à liberdade, à igualdade, à segurança e à propriedade". Entendemos que a pessoa privada de liberdade não deixa de ser um sujeito de direitos, que precisa ser reconhecido como ser dotado de dignidade, entendendo- 
se esta como qualidade inerente à essência do ser humano, bem jurídico absoluto, portanto, inalienável, irrenunciável e intangível. A execução penal, de acordo com os artigos 1 . $^{\circ}$ e 3. ${ }^{\circ}$ da LEP, "tem por objetivo efetivar as disposições de sentença ou decisão criminal e proporcionar condições para a harmônica integração social do condenado e do internado" (p. 1) e a eles “serão assegurados todos os direitos não atingidos pela sentença ou pela lei” (p. 2).

Nesse contexto, o direito à educação está previsto no artigo $5 .^{\circ}$ da Constituição Federal como um direito humano fundamental e subjetivo e tem como objetivos: o pleno desenvolvimento do indivíduo, a promoção da sua cidadania e a sua inserção no mundo do trabalho. Levando em conta tais fundamentos jurídicos, partimos do princípio que a educação é um direito do indivíduo preso e não um benefício, como ainda imaginam algumas pessoas. E que não tem tampouco o objetivo de "docilizar os corpos", mas de promover o previsto na Carta Magna (JULIÃO, 2016).

Esta aproximação entre a educação popular e a EJA em contextos de privação de liberdade é possível porque a Pedagogia do oprimido é um importante referencial teórico para a educação em contextos de privação de liberdade, uma vez que a consciência dos processos de desumanização experimentados nas sociedades de classes é um elemento-chave para uma educação voltada para o resgate da consciência de si dos educandos e educandas como seres humanos e como sujeitos de direitos, independentemente de sua situação jurídica ou penal. A educação popular, portanto, somente pode ser entendida como prática social construída com as classes populares e não para elas; uma educação que busca contribuir para a autonomia, o protagonismo e a luta coletiva das classes populares pela ruptura das relações sociais de opressão, violência e desigualdades de classe, raça, gênero e sexualidade. Nessa perspectiva, não seria possível pensar os sujeitos da educação como objeto da ação do educador ou educadora nem objeto de políticas públicas elaboradas à revelia da participação e das leituras de mundo de educandos e educadores.

Um dos pressupostos deste texto é que a educação popular atualiza-se e se fortalece em todas as formas de defesa dos direitos humanos. Resgatar a consciência de nossa humanidade é sobremaneira importante entre sujeitos reclusos em uma instituição marcada pelo disciplinamento, a redução ou ausência de autonomia, privacidade e participação social, além da violação de direitos indispensáveis a uma vida digna, como denunciam diversos documentos e comissões de direitos humanos ao apresentarem dados do sistema prisional, principalmente sobre violência, mortalidade, doenças, insalubridade, acesso à assistência de saúde, entre outros. 
A pertinência destas reflexões para pensarmos, hoje, sobre a educação em contextos de privação de liberdade é imensa. Para quem tem pouca ou nenhuma aproximação com estes espaços, pode parecer difícil imaginar uma educação pautada no diálogo e na conscientização em uma instituição em que a disciplina procura reduzir ou mesmo anular a autonomia dos indivíduos ao nela ingressarem. No contexto de conservadorismo que temos vivenciado no Brasil, tem sido difícil também o reconhecimento do sujeito apenado como ser humano privado somente do direito de ir e vir na sociedade livre, mas que mantém os seus demais direitos garantidos constitucionalmente pela legislação brasileira como cidadão, principalmente liberdade de consciência, de expressão, de religião e de criação.

Nesse cenário de conservadorismo, o campo de estudos da educação em contextos de privação de liberdade busca destacar a importância da escola como um espaço educativo de liberdade dentro de uma instituição criada justamente para a retirada da liberdade (ONOFRE, 2011). As reflexões deste ensaio confluem para o argumento de que a educação em contextos de privação de liberdade tem potencialidades, assim como dificuldades e contradições, mas isso não impede a criação de processos educativos pautados nos princípios da educação popular.

Todos os espaços e instituições sociais onde a educação acontece são permeados por potencialidades, dificuldades, tensões e contradições. A prisão faz parte deste debate e, portanto, também gera disputas, controvérsias, e seus processos educativos sofrem influência das concepções, experiências e projetos dos sujeitos que atuam na política de execução penal, na política de educação de jovens e adultos em contextos de privação de liberdade.

Diante dos questionamentos e incertezas que permeiam as políticas no Brasil, especialmente a educação em contextos de privação de liberdade, os 50 anos da Pedagogia do oprimido nos convidam a um exercício de leitura do mundo que busque compreender os novos modos de opressão exercidos pelo Estado no Neoliberalismo. A educação dialógica não se resume a uma conversa aleatória: ao contrário, a interação dos sujeitos - educador ou educadora e educandos ou educandas - é um exercício profundo de problematização das diferentes dimensões (históricas, sociais, culturais, políticas, econômicas) que confluem para explicitar as contradições do mundo e dos modos diferentes (e desiguais) de estar no mundo.

Conforme Fiori (1987), no prefácio da Pedagogia do oprimido, os círculos de cultura contribuem para que a consciência emerja do processo de problematização do mundo, que permite ao sujeito compreendê-lo não como um dado natural, mas como projeto humano. Nas palavras do autor: 
Todos juntos, em círculo, e em colaboração, re-elaboram o mundo e, ao reconstruí-lo, apercebem-se de que embora construído também por eles, esse mundo não é verdadeiramente para eles. Humanizado por eles, esse mundo não os humaniza. As mãos que o fazem não são as que o dominam. Destinado a liberá-los como sujeitos, escraviza-os como objetos (FIORI, 1987, s. p.).

Distanciar-se do mundo e compreender os processos de desumanização nele inscritos, conforme Paulo Freire, conduz os sujeitos da educação a distanciarem-se do mundo em que estão inseridos e, portanto, de si mesmos. Esse distanciamento pode ampliar a compreensão das relações sociais que influenciam direta ou indiretamente suas condições materiais e simbólicas de existência. Desse modo, a leitura fatalista, que interpreta o mundo como uma determinação - biológica ou divina - abre espaço para outra leitura, que coloca em dúvida estas determinações e questiona-se sobre o contexto, os sujeitos e as intencionalidades das ações e interações humanas. É nesse sentido que Freire compreende que a educação liberta o ser humano: a problematização do mundo e da própria existência liberta os sujeitos de naturalizar e reproduzir os mecanismos de opressão que os mantém subjugados pelas classes dominantes.

O diálogo implica o reconhecimento do Outro como protagonista de experiências e saberes, ambos marcados por sua posição de classe, raça, gênero e sexualidade. Os breves momentos de atividades educativas que acontecem nas prisões podem funcionar como pequenas janelas, que permitem olhar para fora e enxergar além da realidade imediata, de disciplina e privação de liberdade. Estas janelas não simbolizam a contemplação passiva daquilo que não é possível alcançar - a liberdade -, mas a possibilidade de distanciamento do mundo e de si mesmo, para repensar a própria vida e a das outras pessoas que coabitam a prisão a partir de outras possibilidades de leitura sobre a criminalidade, a violência, o encarceramento e os direitos humanos.

Freire, ao escrever a Pedagogia do oprimido, pensava no contexto histórico em que vivia: desigualdades sociais, pobreza extrema, índices altos de analfabetismo absoluto. Ao longo do livro, suas reflexões sobre a educação contribuíram para a denúncia da educação bancária, conceito elaborado por Freire para analisar as práticas escolares predominantes no contexto histórico dos anos 1970. Para refletir sobre sua atualidade, podemos pensar na educação bancária para além da escola, contemplando também as práticas educativas não escolares, ou seja, as atividades que, embora não estejam vinculadas à instituição escolar, também constituem processos educativos relacionados ao trabalho, à divulgação científica, cultura e arte. Nessa perspectiva, compreendemos que a educação bancária abrange toda experiência educativa que reproduza a desumanização dos oprimidos ao reforçar a ideia de que as classes populares são inferiores e ignorantes, que somente o saber acadêmico é relevante 
para a formação humana e, por isso, não haveria nada o que aprender com os educandos e educandas.

Nos contextos de privação de liberdade do século XXI, o autoritarismo e a desumanização da população prisional estão muito presentes no cotidiano da instituição prisão, como na precariedade do atendimento de saúde física e psíquica, na morosidade da assistência jurídica (o que se comprova com o dado de $40 \%$ da população prisional ser de custódia), na negligência do Estado para garantir material de higiene pessoal, especialmente nos presídios femininos, e na interação embrutecida de agentes operadores da execução penal e trabalhadores de equipamentos públicos acionados para atendimento destas pessoas.

Um aspecto importante sobre a libertação no pensamento freiriano é sua indissociabilidade do engajamento do sujeito nesse processo. $\mathrm{O}$ autor ressalta que não é possível ser objeto da libertação, é necessário o engajamento e o compromisso na luta pela transformação das relações de opressão vigentes na sociedade.

Nas palavras do autor:

Tal liberdade requer que o indivíduo seja ativo e responsável, não um escravo nem uma peça bem alimentada da máquina. Não basta que os homens não sejam escravos; se as condições sociais fomentam a existência de autômatos, o resultado não é o amor à vida, mas o amor à morte. Os oprimidos que se "formam" no amor à morte, que caracteriza o clima da opressão, devem encontrar, na sua luta, o caminho do amor à vida, que não está no comer mais, se bem que também implique nele e dele não possa prescindir (FREIRE, 1987, p. 31).

O indivíduo diante da escolha entre o amor à vida e o amor à morte: esta é uma imagem bastante pertinente à reflexão sobre a educação em contextos de privação de liberdade. A morte compreendida como um conjunto de perdas simbólicas - da liberdade, do convívio familiar e comunitário, da privacidade, dos pertences pessoais - é uma experiência que marca o ingresso na prisão.

Nas palavras de Goffman (1974), o ingresso em instituições totais, como a prisão, o manicômio e o convento, é marcado por rituais de "mortificação do eu", que consistem na retirada de todos os elementos de identidade, de pertencimento individual e social da pessoa privada de liberdade. Pretende-se, com isso, que a pessoa se despoje de sua identidade porque supostamente esta foi a responsável por seu envolvimento com o crime que a levou para a prisão.

Nessa lógica, criticada pelo autor, bastaria que a instituição total moldasse - com disciplina e controle minucioso de todos os gestos, atos, palavras do indivíduo - uma nova identidade, adequada e harmoniosa com a sociedade, o que Goffman definiu como um processo 
de "reorganização do eu". Nada mais precisaria de alteração: estaria tudo certo com as desigualdades sociais, a ausência ou precariedade das políticas sociais nas periferias dos grandes centros urbanos, a concentração de riquezas, o agravamento do desemprego e do trabalho informal e o enrijecimento demasiado da "guerra às drogas". Para se adaptar à prisão, o indivíduo precisa escolher o amor à morte, se considerarmos, como Freire (1987), que a aceitação pelo oprimido da lógica de opressão que se volta contra ele mesmo é uma escolha pelo amor à morte, e não à vida.

É importante compreender esses mecanismos de violência e desumanização dos sujeitos no contexto prisional. A prisão, conforme Wacquant (2011) e Garland (1999), faz parte dos mecanismos coercitivos do Estado para convencer os pobres a não se rebelarem contra as desigualdades sociais, econômicas, políticas e culturais, cada vez mais agravadas pelas políticas do neoliberalismo.

O autoritarismo, a violação de direitos humanos e o descaso do Estado não atingem somente a população privada de liberdade, mas as populações em geral: as classes populares, pela negligência do Estado no combate à pobreza; as classes médias, alienadas pelos discursos sobre criminalidade e violência; e as elites, que fazem do medo e da segurança pública um negócio bastante lucrativo, com a venda de aparelhos eletrônicos de monitoramento de casas, de apólices de seguros para imóveis, automóveis e celulares, para citar apenas alguns exemplos do que a indústria criou no setor da segurança.

Ao mesmo tempo, o tema da segurança torna-se uma justificativa para abrir exceções no que diz respeito à garantia de direitos humanos, a ponto de esvaziar de sentido as instituições que deveriam prezar por tais direitos. Entretanto, aos olhos da opinião pública, os culpados pela violência são justamente os sujeitos que sistematicamente sofrem a violência da violação de direitos indispensáveis à vida digna.

Nas palavras de Freire, quem primeiro produz violência não são os oprimidos, mas sim os opressores, ao desumanizá-los com a exploração, a opressão e o egoísmo de garantirem para si todos os direitos e privilégios em detrimento da maioria da população:

Quem inaugura a negação dos homens não são os que tiveram a sua humanidade negada, mas os que a negaram, negando também a sua. Quem inaugura a força não são os que se tornaram fracos sob a robustez dos fortes, mas os fortes que os debilitaram. Para os opressores, porém, na hipocrisia de sua generosidade, são sempre os oprimidos, que eles jamais obviamente chamam de oprimidos, mas conforme situem, interna ou externamente, de "essa gente" ou de "essa massa cega e invejosa" ou de "selvagens", ou de "nativos", ou de "subversivos", são sempre os oprimidos os que desamam. São sempre eles os "violentos", os "bárbaros", os "malvados", os "ferozes", quando reagem à violência dos opressores (FREIRE, 1987, p. 24). 
Contribuir para que "essa gente" se reconheça como ser humano e, portanto, sujeito de direitos indispensáveis a uma vida digna, em vez de assumirem o estigma de "bandido" ou "monstro", é um compromisso e um desafio centrais da educação popular em contextos de privação de liberdade. Nessa direção, problematizar os processos de criminalização dos pobres é um dos exercícios rumo à ampliação da consciência em contextos de privação de liberdade; nesse exercício, propomos recuperar os estudos de Wacquant $^{4}$ (2011; 2009; 2008).

Nos anos 1970, o avanço das propostas do neoliberalismo nos Estados Unidos foi responsável por uma série de mudanças no mundo. Essas mudanças também ocorreram no modo como o Estado passou a abordar a pobreza e as políticas sociais de assistência aos pobres. A lógica da meritocracia serviu como argumento central para a redução de investimentos públicos para combater a pobreza.

Conforme Wacquant (2011), passou-se do combate à pobreza para o combate aos pobres; ou seja, o problema passou a ser interpretado como responsabilidade única dos indivíduos que se encontram em condições de pobreza. Em outras palavras, o Estado passou a considerar que a culpa pela pobreza é dos pobres, pois em uma sociedade meritocrática cada indivíduo assume a posição social que seu mérito pessoal permite. A lógica perversa da meritocracia, portanto, sustentou, do ponto de vista argumentativo, a redução significativa das políticas públicas voltadas às populações mais pobres, ao passo que as políticas de segurança tiveram aumentos expressivos dos investimentos públicos. Embora a criminalidade não tenha aumentado, a população prisional estadunidense, que até os anos 1970 mantinha-se estável, disparou, e, nas décadas seguintes, aumentou a ponto do país hoje liderar o ranking de países com maiores populações prisionais (WACQUANT, 2009).

O modelo de segurança conhecido como Tolerância Zero ${ }^{5}$ acarretou a ampliação e o enrijecimento dos mecanismos e recursos de controle e vigilância policial sobre os grupos mais pobres e, em especial, dos negros. Conforme Wacquant $(2009$; 2008) analisa em seus estudos, o racismo presente nestas políticas de segurança é responsável pelo fenômeno que definiu como "guetização", um processo de segregação da população negra em guetos, ou seja, em regiões estigmatizadas da cidade como violentas e perigosas, além de isolar os moradores a ponto de prejudicar suas possibilidades de acesso ao trabalho, à escola e outros direitos sociais, e sua circulação pela cidade, que é sistematicamente coibida pelo policiamento - com revistas, checagem de documentos e outros mecanismos de intimidação.

No Brasil, o encarceramento em massa e a seletividade de classe e raça do sistema penal são também uma realidade- A situação prisional brasileira, com as suas especificidades, tem adotado os rumos que o modelo de criminalização dos pobres tomou nos Estados Unidos. Não 
diferente deste país, a maioria da população prisional brasileira é jovem, negra e pobre. Recentemente passamos da $4^{\mathrm{a}}$ para a $3^{\mathrm{a}}$ posição no ranking das maiores populações prisionais do mundo, encarcerando mais de 750 mil pessoas.

Considerando a definição de juventude apresentada no Estatuto da Juventude (BRASIL, 2013), como a fase da vida compreendida entre os 15 e os 29 anos, o que os dados do Infopen (2016) mostram é uma política de penalização da juventude pobre brasileira. Os jovens de 18 a 24 somados aos de 25 a 29 representam $55 \%$ da população prisional do país, apesar de, na distribuição da população disponível no PNAD (IBGE, 2015), as pessoas de 15 a 29 anos representam cerca de $25 \%$ da população brasileira. A sobrerrepresentação dos jovens na distribuição etária da população prisional aliada aos cortes de recursos públicos em políticas sociais desde a aprovação da PEC 55 indica um caminho de criminalização e penalização da juventude pobre brasileira, bastante semelhante à passagem do Estado Providência ao Estado Penal, feita pelo neoliberalismo estadunidense, como analisado por Wacquant $(2011 ; 2009)$.

Todos estes aspectos configuram os moldes específicos dos processos de desumanização na instituição prisional, em que a população encarcerada é objeto de uma educação bancária, às vezes mais sutil, ora mais explícita, mas sempre com o mesmo conteúdo curricular: ensinar aos presos que "direitos humanos são para humanos direitos", o interventor do Rio de Janeiro, em uma de suas primeiras entrevistas, em fevereiro de 2018. Ou seja, na prisão, o Estado ensina que quem está privado de liberdade nem sempre é reconhecido como um ser humano cujas necessidades indispensáveis a uma vida digna serão garantidas. Em poucas palavras, nem sempre é reconhecido como ser humano.

No Brasil dos anos 1970, analisado por Freire, ou no de 2018, que assumiu a 3. a posição no ranking mundial de populações encarceradas, uma das contribuições da educação é trabalhar para que os sujeitos das classes populares reconheçam a própria humanidade e desnaturalizem os processos de desumanização que negam cotidianamente seus direitos a educação, saúde, moradia, trabalho, cultura, esporte e lazer, embora todos eles sejam direitos constitucionais, subjetivos e intransferíveis. Esta é uma condição indispensável para que o ser humano busque a liberdade por meio da educação.

Conforme Freire:

A liberdade, que é uma conquista, e não uma doação, exige uma permanente busca.
Busca permanente que só existe no ato responsável de quem a faz. Ninguém tem
liberdade para ser livre: pelo contrário, luta por ela precisamente porque não a tem.
Não é também a liberdade um ponto ideal, fora dos homens [e das mulheres], ao qual
inclusive eles se alienam. Não é ideia que se faça mito. É condição indispensável ao
movimento de busca em que estamos inscritos os homens [e mulheres] como seres
inconclusos (FREIRE, 1987, p. 18). 
Nessa busca, a libertação não é uma concessão de outrem, não é benefício do Estado nem de qualquer outro agente externo. No pensamento freiriano, a libertação refere-se a um processo interno do próprio oprimido, que toma consciência do mundo e das relações de opressão que configuram sua vida e a si mesmo; a partir desta consciência, liberta-se do opressor que há dentro de si, ou seja, da internalização de prescrições sociais que visam justificar e manter o poder estabelecido, baseado na divisão de classes e na opressão de gênero e raça. Daí a conhecida frase "ninguém liberta ninguém, ninguém se liberta sozinho; os homens libertam-se em comunhão" (id., ibid., p. 27).

Esse processo - Freire é enfático - não envolve assumir o poder e inverter as posições na mesma lógica de reprodução de desigualdades e opressões contra o Outro. Ao contrário, exige romper com esta lógica de opressão para buscar um novo modo de organização da sociedade, ou seja, a transformação social. Nas palavras do autor, “a libertação, por isto, é um parto. Um parto doloroso. O homem que nasce deste parto é um homem novo que só é viável na e pela superação da contradição opressores-oprimidos, que é a libertação de todos" (id., ibid., p. 19).

Nos espaços de educação em privação de liberdade, a problematização destas questões (analisando as concepções de Estado e a meritocracia do neoliberalismo, das mudanças no Estado na organização do trabalho, no mercado e em tantas outras condições materiais e simbólicas da vida humana) faz parte do que Freire definiu como conscientização, ou seja, a tomada de consciência do mundo e de nossa própria posição nas relações sociais em que vivemos. Por meio deste exercício é possível contribuir para que educandos e educandas reconheçam-se como sujeitos de direitos, como seres humanos que, ao longo da vida, lidam com os efeitos das desigualdades sociais que se reproduzem na sociedade brasileira desde o Brasil Colônia; de um modelo de Estado neoliberal, que reduz as políticas sociais e "flexibiliza" a regulamentação dos direitos trabalhistas, ou seja, que abandona as classes populares à própria sorte; da meritocracia, que culpabiliza o indivíduo pelas próprias condições de pobreza, desemprego, baixa escolaridade e outras vulnerabilidades; e de estereótipos contra homens e mulheres pobres - sobretudo homens e mulheres negras - que reforçam a estigmatização destes grupos como preguiçosos, drogados, bandidos, vagabundos e outros. 


\section{Desafios da Educação em Contextos de Privação de Liberdade na Perspectiva da Pedagogia do oprimido}

Para abordar os desafios da educação para jovens e adultos em contextos de privação de liberdade na perspectiva da Pedagogia do oprimido, destacamos inicialmente aspectos que dizem respeito às particularidades do sistema prisional. Em seguida, contemplamos desafios que dizem respeito não somente a este sistema, mas questões que também abrangem, muitas vezes, a política de educação de jovens e adultos como um todo no Brasil.

O primeiro desafio é o de estabelecer confiança, condição imprescindível ao diálogo como criar vínculos de confiança entre educandos/as e educador/a dentro desta instituição que é repleta de desconfiança, onde as pessoas têm permanentemente o receio de que suas palavras sejam incorporadas ao seu "relatório"; onde um colega de cela pode ser o acaguete, que denuncia infrações a um agente ou à Direção.

Ainda sobre este desafio, trabalhar a confiança dos demais agentes operadores da execução penal em relação aos apenados é outra dimensão do mesmo problema. Conforme Freire, quem não tem fé nos homens, quem não reconhece no outro um sujeito e o reduz a "essa gente", julgando-o e olhando-o com superioridade, não pode estabelecer um diálogo autêntico. Se considerarmos que, na prisão, a educação não acontece exclusivamente na escola, temos que pensar que todos os agentes que nela atuam têm em seu fazer cotidiano uma dimensão educativa. Seu trabalho obviamente não é o da educação escolar, mas contribuem para a educação não escolar da população prisional.

Outro desafio próprio dos contextos de privação de liberdade diz respeito ao cotidiano da prisão, principalmente em seus aspectos administrativos, o que leva, não raro, a um conflito entre a educação e a segurança. Melhor dizendo, da sobreposição da segurança sobre a educação. Tudo envolve negociações: desde a entrada do/a educador/a no estabelecimento prisional (que geralmente é reconhecido fora do quadro dos agentes operadores da política de execução penal), a avaliação sobre a periculosidade de cada material de trabalho, até o tempo de duração da aula.

A autonomia de trabalho do educador na prisão também está sujeita ao crivo da segurança e pode passar pelo convencimento da direção da unidade penal e dos agentes penitenciários. A lógica de gestão tem variações, de acordo com a política de governo em vigência, com as concepções de trabalho do diretor ou diretora da unidade penal, que, em alguns casos - à luz do que Goffman (1974) chama de "instituição total” -, lida com o estabelecimento prisional como se fosse de sua propriedade pessoal. Consequentemente se a sua compreensão sobre a educação for de que esta é desnecessária, é um privilégio e não um direito, a entrada de 
educadores/as encontrará todos os obstáculos possíveis: desde justificativas burocráticas até impedimentos sem explicação, morosidade para obter autorizações para realização de projetos, entre outros.

Em estabelecimentos em que a autorização e a aceitação de projetos educativos por parte de quem dirige a unidade são positivas, as condições de trabalho ainda assim não estão garantidas. Muitos fatores influenciam o trabalho, como a postura dos agentes, dos técnicos principalmente quanto a sua disponibilidade em contribuir para o convencimento dos e das apenado/as sobre a importância da atividade -, além das condições de infraestrutura, como a disponibilidade de sala, a possibilidade de entrada de materiais e equipamentos para o trabalho.

Dentre os desafios da educação popular em contextos de privação de liberdade, tomando como base os conceitos de dialogicidade e conscientização, ressaltados por Freire, destacamos a importância de promover, na escola da prisão, um processo educativo antagônico às práticas autoritárias e desumanizadoras denunciadas. A dialogicidade é compreendida como a base de uma educação libertadora. Esta não age sobre os sujeitos, tomando como objeto os homens e mulheres que dela participam - e esta é uma importante ruptura em relação à educação bancária, pois tem como pressuposto que educandos e educandas são sujeitos com experiências e saberes produzidos nas culturas populares em que estão inseridos.

Sem esse reconhecimento, não poderia existir educação libertadora, no entender de Freire, nem pode existir hoje a educação popular em contextos de privação de liberdade. Nestes contextos, permanece atual e urgente o compromisso da educação com o resgate da humanidade de sujeitos historicamente desumanizados, ou seja, sujeitos cujos direitos indispensáveis a uma vida digna têm sido sistematicamente negligenciados pelo Estado, com o apoio deliberado ou a conivência das elites empresariais e de grupos políticos e religiosos conservadores.

Além de todos estes aspectos, se considerarmos as reflexões de Garland (1999) a respeito das mudanças do papel da prisão na sociedade contemporânea, entendemos que a educação em contextos de privação de liberdade encontra outro paradoxo que desafia docentes e estudantes, assim como os sujeitos envolvidos em atividades não escolares: como lidar com a perspectiva da educação popular que visa contribuir para a consciência crítica do educando em um espaço em que a manutenção da "calma" é uma prioridade para a maioria dos agentes operadores da execução penal? Nessa direção, como refletir sobre uma sociedade que produz pobreza e desigualdades, prioriza políticas penais em vez de políticas sociais de garantia de direitos humanos, sem abalar esta "calma"?

Quem atua em contextos de privação de liberdade, seja como docente, pesquisador ou pesquisadora, já ouviu como elogio que sua presença e interação com os/as apenado/as os ajuda 
a se manterem "calmos". E se esta interação não tiver o efeito calmante almejado pelos trabalhadores da unidade?

Criar um equilíbrio entre o que a equipe espera do trabalho do/a educador/a e, por outro lado, o que é compromisso da educação popular é um desafio que exige reflexão coletiva, troca de experiências e um esforço de formação continuada de profissionais que atuam no sistema prisional, o que está previsto nos planos estaduais de educação em prisões, elaborados em 2012 em atendimento à demanda do Departamento Penitenciário Nacional do então Ministério da Justiça e Segurança Pública (DEPEN) ${ }^{7}$.

Outros questionamentos desafiam a educação popular em contextos de privação de liberdade. Eles não são impeditivos para justificar a ausência da política de educação nestes espaços. A depender do comprometimento de quem se engaja na proposta de educação popular nestes espaços, a indagação é o que possibilita a busca de saber mais para ser mais, como o próprio Freire $(1979 ; 1987)$ afirmou. Como produzir uma práxis libertadora em um espaço rígido e hierarquicamente controlado, sob o argumento de que qualquer ínfima alteração coloca em risco a segurança do estabelecimento e, portanto, das pessoas ali presentes? Como almejar a autonomia do sujeito em uma instituição cujos princípios basilares são o controle, a sujeição e o disciplinamento, ou, retomando conceitos elaborados por Goffman (1974) para analisar as instituições totais, os processos de mortificação e de reorganização do eu?

Lidar com estas perguntas é muito provocador, na medida em que possibilita recriar a educação popular, em espaços e condições de trabalho específicos, com potencialidades e obstáculos também específicos. No final dos anos 1980 Freire se desafiou a pensar sobre as possibilidades de levar a educação popular a um contexto até então inédito, o da escola pública. Daquelas indagações, nasceram o Movimento de Alfabetização de Jovens e Adultos - MOVASP, depois o MOVA-RS e inúmeras outras experiências de escolarização de jovens e adultos, assim como de crianças.

Tomar Paulo Freire como um educador inclusivo significa, no campo de educação com jovens e adultos em espaços de privação de liberdade, construir conhecimentos que considerem a diversidade de visões de mundo das pessoas envolvidas em situações limite e favorecer o processo de humanização. Não se trata, no dizer de Araújo-Oliveira (2014), de dar consciência aos oprimidos, pelo contrário, eles próprios a tomam ao examinar e criticar os atos do seu cotidiano que cumprem como rotina. Para a autora, as comunidades de oprimidos: 
Com consciência de sua condição como tal e por meio do diálogo intersubjetivo, descobrem, analisam, estruturam e validam um projeto alternativo factível que concretize, ou aproxime estrategicamente, a realização do projeto utópico, o inédito viável (ARAÚJO-OLIVEIRA, 2014, p. 85).

Importante registrar que tomar consciência das situações-limites requer momentos de convívio com os pares, nas mais diversas práticas sociais que acontecem nas celas, nos espaços do banho de sol, na escola, nos espaços de trabalho, nos cultos religiosos, no espaço de visitas, nas rodas de conversa, nas oficinas profissionalizantes, entre tantas outras. São momentos em que o indivíduo pode identificar como o seu modo de viver é produzido por situações-limite. Estamos diante de pessoas que pensam, sentem, cultivam sonhos, são - como somos sempre seres inconclusos!

As situações-limites do presente podem levá-los a acreditar que estas foram produzidas por determinações históricas do passado e ali se encontram para 'pagar' e silenciar. Ora, que passado lhes foi oferecido? Iniciam a 'carreira delitiva' no momento que transgridem a lei e, portanto, devem ser alijados dos seus direitos, em favor dos homens de bem? Passado e futuro são, respectivamente, o período anterior e o posterior à reclusão? O estigma e a marginalização instituem-se no momento do aprisionamento?

Como adverte Cunha (2008), os referentes do futuro, tal como os do passado, se encontram, em parte, incorporados na prisão, pois o passado pode estar situado no período da pré-reclusão e os planos para o futuro são modestos, comedidos e destinados a reparar os estragos que a reclusão terá provocado.

Nessa direção, Freire (1980) anuncia a educação problematizadora como possibilidade de os oprimidos desenvolverem um pensamento crítico sobre as situações-limites, que marcam seu cotidiano e sua realidade. A conscientização se constitui em mecanismo de desvelar as situações existenciais opressoras com base em uma pedagogia da denúncia dessas situaçõeslimites e em uma pedagogia do anúncio de um inédito viável a ser experimentado.

Está posto o desafio que Freire captou com intuição e sensibilidade: as situações-limites de nossos tempos de opressão, de práticas elitistas e autoritárias. O inédito viável anuncia o sonho utópico. O anúncio de generosidade, de humanismo e de esperança de futuro - "o inédito viável é, pois, uma categoria que encerra nela mesma toda uma crença no sonho e na possibilidade da utopia" (id., ibid., p. 124).

Além disso, hoje novamente estamos diante do desafio de resistir aos ataques de grupos conservadores contra os direitos humanos. Novamente, como no período da ditadura militar, a opinião pública corrobora a perseguição de quaisquer ideias progressistas, estereotipadas como "esquerdistas", "ideológicas" e "comunistas" por grupos conservadores. Hoje, no entanto, a 
sensação de insegurança e de ameaça à propriedade privada, associada ao desemprego e à ameaça de empobrecimento parecem criar as condições ideias para o fortalecimento de discursos de ódio e ataques aos direitos humanos; de combate ao que se chama "uso ideológico", porque consideram que somente o pensamento progressista é ideológico e que o pensamento conservador seria isento de ideologia.

Indissociável dos desafios mencionados é encontrar brechas na política de execução penal para colocar em xeque esta instituição e avançar na produção de estratégias para o desencarceramento. Onofre (2016) sugere pensarmos as práticas sociais que acontecem na instituição prisão, pois esta pode ser uma forma de abrir pequenas fendas que podem anunciar possibilidades de enfrentamento dos paradoxos entre punir e educar. Nesse sentido, analisar a prisão como instituição socioeducativa nos leva a sinalizar a relevância de se tomar as práticas que ali acontecem como práticas que educam, uma vez que nelas se estabelecem o convívio, as aprendizagens e o respeito ao outro.

De igual forma, para sobreviver na prisão, as pessoas em privação de liberdade assumem a duplicidade, a máscara, o jogo do olhar, o vocabulário, o silêncio, que também se constituem em aprendizagens - portanto, experienciam, refletem, alavancam ferramentas pra sobreviver.

Embora reconheçamos a prisão como instrumento punitivo, que desestrutura as pessoas, ela própria cria mecanismos de resistência que lhe permitem sobreviver. No entender de Onofre:

[...] não se trata de aprendizagem negativa ou positiva, mas ao recriar o espaço da vida, as pessoas em privação de liberdade, ressignificam a sua estadia no momento, experienciam outras visões de mundo, e isso significa sabedoria. (ONOFRE, 2016, p. 49).

Nessa direção, Dussel) afirma: “... mesmo na extrema humilhação da prisão, no frio da cela e a dor total da tortura, embora seu corpo fosse apenas uma chaga viva, ainda pode clamar - Sou outro, sou um homem, tenho direitos!” (2000, p. 57.

Enfrentar todos estes desafios não é simples nem rápido, porém há que se criar as condições para, no futuro, superar a lógica "punitivista". A esse respeito, Ângela Davis propõe que, para imaginar a abolição das prisões, o caminho não é procurar substituições à instituição prisional, mas, sim, romper com a lógica de punição da população pobre e negra:

[...] colocando o desencarceramento como nossa estratégia global, tentaríamos imaginar um continuum de alternativas ao encarceramento - a desmilitarização das escolas, a revitalização da educação em todos os níveis, um sistema de saúde que ofereça atendimento físico e mental gratuito para todos e um sistema de justiça baseado na reparação e na reconciliação em vez de na punição e na retaliação. (...) Para reiterar, em vez de tentar imaginar uma única alternativa ao sistema de encarceramento existente, temos que imaginar uma série de outras que exigirão transformações radicais em muitos aspectos da nossa sociedade. Alternativas que não 
combatam o racismo, a dominação masculina, a homofobia, o preconceito de classe e outras estruturas de dominação não levarão, em última análise, ao desencarceramento e não promoverão o objetivo da abolição. (2018, p. 116-117)

Pensar em alternativas ao encarceramento em massa faz parte do mais urgente dos desafios não só da educação, mas da sociedade em geral: o de resgatar nossa humanidade - a humanidade de toda a sociedade. Afinal, a prisão não é uma instituição social isolada do mundo. Nesse sentido, como instituição social, a prisão é criação, responsabilidade de toda a sociedade e, portanto, a desumanização dos sujeitos dentro das prisões desumaniza cada uma de nós.

\section{4 À Guisa de Conclusão}

A educação em contextos de privação de liberdade é o campo de reflexão e prática a que nos dedicamos como pesquisadores/as. Aproximar este campo de atuação da educação popular e, em especial, dos conceitos e reflexões elaborados por Freire na obra Pedagogia do oprimido, que completou 50 anos em 2018, não é apenas um exercício analítico para atender à chamada deste dossiê. É também uma opção político-epistemológica e pedagógica que orienta nossos estudos e intervenções em ensino, pesquisa e extensão.

Compreendemos que a defesa do direito à educação precisa atingir os grupos mais vulneráveis das sociedades contemporâneas; e a população prisional brasileira, em sua maioria é formada por pessoas pobres, negras, com baixa escolaridade, que não tiveram acesso a políticas sociais de saúde, educação, moradia, trabalho, assistência social, e que dirá de cultura, esportes e lazer.

Ao longo deste ensaio, buscamos argumentar sobre as possibilidades de releitura da obra Pedagogia do oprimido em contextos de privação de liberdade. Em outras palavras, defendendo uma proposta político pedagógica para a educação no ambiente prisional alicerçada nos preceitos da educação popular, retomamos conceitos desenvolvidos por Freire na obra em questão para problematizar os mecanismos de opressão contra as classes populares nos dias atuais, em especial nos contextos de privação de liberdade, embora em vários aspectos a leitura de questões contemporâneas à luz dos conceitos freirianos diga respeito a toda a sociedade.

Também refletimos sobre os desafios da educação popular em contextos de privação de liberdade. Em síntese, elencamos os seguintes desafios: garantir o direito à educação para os grupos sociais mais vulneráveis e estigmatizados nos dias atuais; avançar no que diz respeito à qualidade da educação de jovens e adultos; resistir aos ataques de grupos conservadores contra os direitos humanos; e encontrar brechas no sistema penitenciário para colocar em xeque esta instituição e avançar na produção de alternativas ao encarceramento em massa. 
Muitas questões permanecem em aberto a partir das reflexões que desenvolvemos neste texto. Quiçá estas aberturas estimulem outras pessoas a pesquisarem o tema, a darem continuidade a estas indagações a fim de ampliar e consolidar o debate sobre as confluências entre a educação em contextos de privação de liberdade e o legado de Paulo Freire e da educação popular.

${ }^{1}$ Aqui grafada com maiúsculas porque se trata de uma denominação específica dada pelo Brasil e alguns países da América Latina à Educação de Adultos (EdA).

${ }^{2}$ Embora a notícia não seja de uma fonte acadêmica, ela sugere aspectos relevantes para a discussão deste artigo sobre as condições materiais e simbólicas do debate sobre a educação em contextos de privação de liberdade. Disponível em: 〈https://www.bbc.com/portuguese/brasil-44148576>.

${ }^{3}$ Ainda não foram julgados; estão presos em caráter provisório.

${ }^{4}$ Sociólogo estadunidense conhecido por analisar a passagem do Estado Providência para o Estado Penal a partir da realidade do seu país e depois comparando com alguns países europeus, em especial a França.

${ }^{5}$ Este modelo de segurança consiste, em síntese, no endurecimento das penas para pequenos delitos e no enrijecimento do controle das populações consideradas "perigosas" com ampliação do policiamento e dos recursos de fichamento, controle, vigilância das pessoas que moram em bairros pobres das grandes cidades.

${ }^{6}$ Este modelo de segurança consiste, em síntese, no endurecimento das penas para pequenos delitos e no enrijecimento do controle das populações consideradas "perigosas" com ampliação do policiamento e dos recursos de fichamento, controle, vigilância das pessoas que moram em bairros pobres das grandes cidades.

${ }^{7}$ Este modelo de segurança consiste, em síntese, no endurecimento das penas para pequenos delitos e no enrijecimento do controle das populações consideradas "perigosas" com ampliação do policiamento e dos recursos de fichamento, controle, vigilância das pessoas que moram em bairros pobres das grandes cidades.

\section{Referências}

ARAÚJO-OLIVEIRA, Sonia Stella. Exterioridade: o outro como critério. In: OLIVEIRA, Maria Waldenez de; SOUSA, Fabiana Rodrigues de (Org.). Processos educativos em práticas sociais: pesquisas em educação. São Carlos: EduFSCar, 2014, p. 47-112.

BRASIL. Lei no 12.852/2013. Estatuto da Juventude. Brasília: Câmara dos Deputados, 2013.

BRASIL. Constituição da República Federativa do Brasil. Brasília: Câmara dos Deputados, 1988.

BRASIL. Lei no 7.210/1984. Lei de Execução Penal. Brasília: Câmara dos Deputados, 1988.

CUNHA, Manuela Ivone Cunha. O tempo insuspenso: uma aproximação a duas percepções carcerais da temporalidade. In: ARAÚJO, Emília; DUARTE, Ana Maria; RIBEIRO, Rita (Org.). O tempo, as culturas e as instituições: para uma abordagem sociológica do tempo. Lisboa: Colibri, 2008, p. 91-104.

DAVIS, Ângela. Estarão as prisões obsoletas? Rio de Janeiro: Rocco, 2018.

DUSSEL, Enrique. Ética da libertação: na idade da globalização e da exclusão. Petrópolis: Vozes, 2000. 
FIORI, Ernani. Aprender a dizer a sua palavra. In: FREIRE, Paulo. Pedagogia do oprimido. 17. ed. Rio de Janeiro: Paz e Terra, 1987.

FREIRE, Paulo. Educação e mudança. Rio de Janeiro: Paz e Terra, 1979.

FREIRE, Paulo. Conscientização - teoria e prática da libertação: uma introdução ao pensamento de Paulo Freire. São Paulo: Moraes, 1980.

FREIRE, Paulo. Pedagogia do oprimido. 17. ed., Rio de Janeiro: Paz e Terra, 1987.

GOFFMAN, Ervin. Manicômios, prisões e conventos. São Paulo: Perspectiva, 1974. (Coleção Debates, 91).

GARLAND, David. As contradições da "sociedade punitiva": o caso britânico. Revista de Sociologia Política, n. 13, Universidade Federal do Paraná, Curitiba, nov. 1999, p. 59-80. IBGE. PNAD 2015. Disponível em:

<https://biblioteca.ibge.gov.br/visualizacao/livros/liv98887.pdf>. Acesso em: 10 set. 2018.

INFOPEN. Departamento Nacional Penitenciário. 2016. Disponível em:

<http://depen.gov.br/DEPEN/depen/sisdepen/infopen/apresentacao-coletiva-08-12-2017.pdf>. Acesso em: 10 set. 2018.

JULIÃO, Elionaldo Fernandes. Educação da ou na prisão? Caderno Cedes, v. 36, n. 98, p. 25-42, 2016. Disponível em: <http://www.scielo.br/scielo.php?pid=S010132622016000100025\&script=sci_abstract\&tlng=pt>. Acesso em: 10 set. 2018.

ONOFRE, Elenice Maria Cammarosano. O Papel da Escola na Prisão: Saberes e experiências de alunos e professores. Childhood \& Philosophy (online), v. 7, jul.-dez. 2011. Disponível em: <http://www.redalyc.org/articulo.oa?id=512051604008>. Acesso em: 10 set. 2018.

ONOFRE, Elenice Maria Cammarosano. A prisão: instituição educativa? Educação, escolarização e trabalho em prisões: apontamentos teóricos e reflexões do cotidiano. Cadernos Cedes, Campinas, v. 36, p. 43-59, 2016. Disponível em: <http://www.scielo.br/scielo.php?script=sci_arttext\&pid=S0101-32622016000100001>. Acesso em: 10 set. 2018.

WACQUANT, Loïc. As duas faces do gueto. São Paulo: Boitempo, 2008.

WACQUANT, Loïc Punir os pobres: a nova gestão da miséria nos Estados Unidos. Rio de Janeiro: Revan, 2009

WACQUANT, Loïc As prisões da miséria. Rio de Janeiro: Jorge Zahar Editor, 2011. 